\title{
Vivências de Protagonismo Socioambiental por Jovens: Implicações na Constituição do Sujeito Ético-Político
}

\author{
Iolete Ribeiro da Silva ${ }^{1}$ \\ Orcid.org/0000-0002-9416-6866 \\ André Luiz Machado das Neves ${ }^{2, *}$ \\ Orcid.org/0000-0001-7400-7596 \\ Fernanda Priscilla Pereira Callegare ${ }^{3}$ \\ Orcid.org/0000-0002-0671-7243 \\ Maria Inês Gasparetto Higuchi ${ }^{4}$ \\ Orcid.org/0000-0001-6525-4018 \\ Eleonora Celeste Farkas Félix Pereira ${ }^{1}$ \\ Orcid.org/0000-0001-5600-5642
}

\author{
${ }^{1}$ Universidade Federal do Amazonas, Manaus, AM, Brasil \\ ${ }^{2}$ Universidade do Estado do Amazonas, Manaus, AM, Brasil \\ ${ }^{3}$ Tribunal de Justiça do Estado do Amazonas, Manaus, AM, Brasil \\ ${ }^{4}$ Instituto Nacional de Pesquisas da Amazônia, Manaus, AM, Brasil
}

\section{Resumo}

Este artigo apresenta um estudo acerca de vivências de protagonismo juvenil por jovens que atuam em um coletivo socioambiental. Configurou-se numa pesquisa de campo de abordagem qualitativa, da qual participaram três integrantes de um coletivo jovem de ações socioambientais. Os dados foram coletados por meio de um grupo focal e analisados por intermédio da análise construtiva-interpretativa. $\mathrm{O}$ estudo se desenvolve em torno dos conceitos teóricos de protagonismo juvenil e socioambiental, de vivência e de sujeito ético-político. Os resultados indicam que as vivências de protagonismo juvenil pelos jovens são produto e produtoras de novas relações entre si e com os outros seja por meio de transformação pessoal, pela promoção de autonomia coletiva, pela possibilidade de organização sociopolítica e pela ampliação do compromisso coletivo político. As conclusões indicam que vivenciar as atividades socioambientais possibilitou aos jovens o fortalecimento do compromisso social e político, além da conscientização enquanto agentes transformadores da sua realidade, de si e do outro, com relação aos cuidados com o meio ambiente. Demonstrando, desta maneira, uma preocupação solidária, balizada numa conduta ético-política.

Palavras-chave: Jovens, meio ambiente, sujeito ético-político, Educação ambiental.

* Endereço para correspondência: Avenida Professor Nilton Lins, 2401, Parque das Laranjeiras, Condomínio Brisas do Parque, apto 105, torre 04, Manaus, AM, Brasil 69058-030. E-mail: andre_machadostm@hotmail. com

Fomento: Fundação de Amparo à Pesquisa do Estado do Amazonas - FAPEAM. 


\title{
Experiences of Environmental Leadership by Young People: Implications for the Constitution of the Ethical-Political Subject
}

\begin{abstract}
This article presents a study about youth protagonist experiences of young people who take part in a social and environmental collective. It sets up an exploratory field research with a qualitative approach, which was attended by three members of a young collective of social-environmental actions. Data were collected by conducting a focus group and analyzed through constructive-interpretative analysis. The study revolves around the theoretical concepts of youth and the environmental role of experience and the ethical-political subject. The results indicate that youth protagonist experiences of participation by young people are products and producers of new relationships with each other, and others will be through personal transformation, by collective autonomy promotion, by the possibility of sociopolitical organization and by the expansion of the political collective commitment. The findings indicate that experiencing social and environmental activities made it possible for young people to strengthen social and political commitment and increased awareness as agents of change in their reality, in themselves and others, with respect to caring for the environment; thus, in this way demonstrating a caring concern, buoyed in ethical political conduct.
\end{abstract}

Keywords: Youth, environment, ethical-political subject, Environmental education.

\section{Experiencias de Liderazgo Ambiental por los Jóvenes: Implicaciones para la Constitución del Sujeto Ético-Político}

\section{Resumen}

En este artículo se presenta un estudio sobre el protagonismo juvenil de experiencias para los jóvenes que trabajan en un colectivo social y ambiental. Se establece un campo de investigación exploratoria de carácter cualitativo, a la que asistieron tres miembros de un joven colectivo de acciones ambientales. Los datos fueron recolectados mediante la realización de un grupo de enfoque y se analizaron mediante un análisis constructivo-interpretativo. El estudio gira en torno a los conceptos teóricos de la juventud y la relevancia medioambiental de la experiencia y el sujeto ético-política. Los resultados indican que las experiencias de participación de los jóvenes por los jóvenes son el producto y la producción de nuevas relaciones entre sí y la otra es a través de la transformación personal, la promoción de la autonomía colectiva, la posibilidad de organización sociopolítica y la expansión del compromiso colectivo político. Los resultados indican que la experiencia de las actividades sociales y medioambientales hacen posible que las personas jóvenes para fortalecer el compromiso social y político y una mayor conciencia como agentes de cambio en su realidad, usted y la otra con respecto al cuidado del medio ambiente. Demostrando de esta manera una preocupación cuidar, impulsado en una conducta ética política.

Palabras clave: Juventud, medio ambiente, sujeto ético-política, la educación ambiental.

A concepção de vivência, na qual este estudo se ancora, pauta-se na premissa de que a pessoa se constitui politicamente integrada à sua realidade. Assim sendo, compreende-se, na perspectiva de Freire (2001), a vivência como possibilidade humana de existir, enquanto um ser eminentemente relacional, dinâmico, concreto, histórico e cultural, que modifica e é modificado a partir da interação social e da conscientização que se procede dessas experiências. Dito de outra forma, a tomada de consciência acerca de seu posicionamento no mundo, possibilita a transformação das relações do sujeito consigo e com seu entorno, processo que se constitui no 
fenômeno compreendido como vivência (Freire, 2001).

É neste ínterim, vinculado ao conceito de vivência, que se compreende o sujeito ético-político como construído a partir das suas experiências relacionais, implicadas com a individualidade, a coletividade e o mundo. Tornar-se sujeito ético-político é vivenciar o processo de emancipação, com responsabilidade social e política, construindo um entendimento da sociedade através de uma concepção mais solidária e interdependente (Freire, 2000).

Estes conceitos dialogam com o de protagonismo, compreendido por Silva (2010) como o processo de superar as adversidades, resistir às pressões, modificar sua realidade e adaptar-se às exigências do mundo atual. No contex to do meio ambiente, o protagonismo socioambiental surgiu a partir dos anos 80 , como consequência de movimentos sociais interessados em preservar o meio ambiente (Ziglio, 2012). Esses grupos direcionam o esforço coletivo em ações cívicas intencionais e deliberadas para mudar causas sistêmicas de problemas ambientais e promover um ambiente sustentável (Alisat \& Riemer, 2015). Esse movimento ganhou destaque em decorrência dos problemas ambientais cada vez mais emergentes, com a preocupação em reverter esse cenário e transformar a forma da sociedade se relacionar com o meio ambiente.

No contexto juvenil, os jovens que participam de grupos socioambientais estão engajados na luta por um meio ambiente saudável para a sociedade e, por meio de atividades de Educação Ambiental, buscam sensibilizar as pessoas para preservar o meio ambiente. Pesquisas indicam que os jovens envolvidos nesses grupos desenvolvem a compreensão acerca de meio ambiente de maneira crítica e organizados politicamente (Albuquerque, 2012).

Nessa acepção, Lazzaretti de Souza, Finkler, Dell $>$ aglio e Koller (2010) definem que o protagonismo juvenil socioambiental se caracteriza a partir de ações que têm acontecido em âmbitos diferenciados, enfatizando a importância dos jovens por meio de atividades que afirmem o engajamento e a mobilização social. Fomentar o protagonismo dos jovens ancora-se no reconhe- cimento da sua capacidade de perceber o ambiente de forma crítica e, a partir disso, assumir uma postura ativa no que se refere à construção de alternativas para melhoria das realidades sociais.

O Ministério do Meio Ambiente - MMA (2005), durante a I Conferência Nacional Infanto-Juvenil pelo Meio Ambiente numa tentativa de afirmar o reconhecimento da capacidade do jovem de engajar-se coletivamente e atuar no âmbito socioambiental, propôs a criação dos Conselhos Jovens, que posteriormente passaram a ser chamados Coletivos Jovens de Meio Ambiente. A criação de tais grupos visava a construção de espaços em que jovens pudessem refletir coletivamente as demandas locais e construir propostas de melhorias para o contexto no qual estavam inseridos. Reflete-se, portanto, sobre o conceito de protagonismo juvenil, trazendo à tona um tema que tem sido discutido em vários contextos, mas que ainda se mantém pouco explorado, principalmente no que diz respeito a temáticas de educação ambiental e constituição do sujeito ético-político.

Frente a essas questões, este artigo tem a finalidade de analisar as vivências do protagonismo juvenil por um coletivo de jovens (CJ) e problematizar em que medida essa forma de participação juvenil se converte em formas de participação política dos jovens.

\section{Método}

Desenvolveu-se uma pesquisa de campo, de abordagem qualitativa, para analisar as vivências do protagonismo juvenil dos participantes. Adotou-se como perspectiva a Epistemologia Qualitativa de González Rey (2011) que apresenta três princípios norteadores para a pesquisa qualitativa: a defesa pelo caráter construtivo interpretativo do conhecimento, tendo em vista que este é uma produção humana; a legitimação do singular como instância de produção do conhecimento científico; e a compreensão da pesquisa como um processo essencial de comunicação. Assim, a metodologia desta pesquisa se orienta na direção da construção de modelos compreensivos do fenômeno estudado, buscando desenvolver espaços de inteligibilidade sobre o tema. 


\section{Contexto e Participantes da Pesquisa}

A pesquisa foi realizada com integrantes do Coletivo Jovem de Meio Ambiente (CJ) de Iranduba, cidade da região metropolitana de Manaus. Os integrantes do CJ começaram a se articular em 2003, quando participaram da Conferência Nacional Infanto-Juvenil pelo Meio Ambiente, na qual se comprometeram a levar as discussões desenvolvidas durante a conferência para as suas cidades, o que ficou marcado como os primeiros sinais de organização do coletivo. No ano de 2006 o CJ foi oficializado, com a participação no "Show das Águas, Meio Ambiente e Cidadania", uma ação desenvolvida pela Fundação Rede Amazônica, que visa desenvolver ações de cidadania nas comunidades do Amazonas. $\mathrm{Na}$ ocasião, o CJ desenvolveu oficinas de educação ambiental nas escolas da rede pública de ensino, momento em que sentiram a necessidade de maior articulação e unidade do coletivo.

Desde então, o CJ vem atuando nas atividades de cidadania e educação ambiental no município de Iranduba. Atualmente desenvolve ações de educação ambiental e de articulação política da juventude da cidade, promove discussão acerca dos direitos da juventude, estatuto da juventude, a política nacional da juventude e sobre as demandas locais da juventude, bem como pensa e constrói formas de enfrentamento aos problemas vivenciados pela juventude local. Também fazem parte da atuação do CJ, ações em parceria com a Secretaria Estadual de Educação (SEDUC), desenvolvendo atividades durante o "Show das Águas, Meio Ambiente e Cidadania" em escolas estaduais e no "Projeto Permanecer", que visa estimular a permanência dos jovens nas escolas, atuando em escolas da periferia, que apresentam alto índice de evasão escolar nas séries finais.

O contato com os jovens integrantes do CJ se deu porque estes participavam de uma atividade de pesquisa ${ }^{1}$ no Laboratório de Psicologia

Projeto de pesquisa financiado pelo Conselho Nacional de Desenvolvimento Científico e Tecnológico (CNPQ), por meio do Edital Universal 2012, com duração de 2012 a 2014, denominado Protagonismo juvenil: aspectos constitutivos e e Educação Ambiental do Instituto Nacional de Pesquisas da Amazônia - INPA, coordenado pela terceira autora. Foi feito o convite para a pesquisa e aceitaram participar três membros (1F; 2M), líderes do CJ. Para a garantia do anonimato dos participantes, eles foram identificados com as seguintes siglas (JF1; JM2 e JM3) A letra $\mathrm{J}$ representa Jovem, a segunda letra representa o gênero $(\mathrm{M}=$ masculino e $\mathrm{F}=$ feminino $)$ e os números de acordo com a sequência inicial de participação do grupo. Os participantes eram provenientes de família com baixo poder aquisitivo, com idade de 18 (JM 1 e JM2) e 17 (JM3) anos. Dois deles (JM1 e JM2) residiam em um município da região metropolitana da cidade de Manaus e estudavam na capital e JM3 estava residindo na zona leste de Manaus. JM1 e JM2 eram estudantes universitários e JM3 estudante do ensino médio.

Foram resguardados os aspectos éticos, com a assinatura do Termo de Consentimento Livre e Esclarecido, por todos os participantes, no qual primou-se pelos princípios de confidencialidade, participação voluntária e acolhimento dos riscos da pesquisa. O projeto foi submetido e aprovado pelo Comitê de Ética em Pesquisa do INPA, sob o parecer de $\mathrm{n}^{\mathrm{o}} 231.007$.

\section{Instrumento}

A coleta de dados foi realizada por intermédio de grupo focal, com duração de uma hora. Foram realizados dois encontros com os jovens, em 2014, no Laboratório de Desenvolvimento Humano e Educação da Faculdade de Psicologia da Universidade Federal do Amazonas (UFAM). Após o convite à participação, foram marcados os encontros no laboratório, que era o local que tinha espaço disponível para a realização do grupo. O primeiro encontro foi realizado para explicar os objetivos, a metodologia da pesquisa, os aspectos éticos e a voluntariedade da participação, bem como promover vinculação inicial com os participantes da pesquisa. $\mathrm{O}$ segundo desenvolveu-se o Grupo Focal em si, com o de-

implicações psicossociais da mobilização e participação em atividades socioambientais de jovens na região metropolitana de Manaus- AM. 
senvolvimento da conversa a partir das seguintes perguntas norteadoras: O que é ser um jovem ambientalista? $\mathrm{O}$ que é necessário para ser um jovem ambientalista? Quais as transformações sociais que a atuação de vocês trouxe para a comunidade por meio do CJ? Que conquistas pessoais foram agregadas a partir da participação no CJ? Os dados foram registrados em um gravador de áudio MP3. Os tópicos que os pesquisadores consideram mais relevantes e norteadores do conteúdo produzido durante o grupo foram anotados em um livro ata.

\section{Análise de Dados}

As informações produzidas na pesquisa a partir do grupo focal foram analisadas com base no processo de construção da informação na perspectiva da Epistemologia Qualitativa, conforme define González Rey $(2011$, p. 4) “a pesquisa qualitativa que assume os princípios da Epistemologia Qualitativa se caracteriza pelo seu caráter construtivo-interpretativo, dialógico e pela sua atenção ao estudo dos casos singulares".

Desse modo, as informações foram analisadas a partir da perspectiva construtivo-interpretativa (González Rey, 2003, 2011). O caráter construtivo-interpretativo do conhecimento, concebe a realidade como um domínio infinito de campos inter-relacionados de maneira complexa, da qual é possível aproximar-se de parte, por meio das práticas de investigação, mas não da sua totalidade. Essa premissa embasa a compreensão do conhecimento enquanto produção humana e não como apropriação linear da realidade estudada.

A pesquisa, nesse sentido, primou pela adoção de um caráter ativo e de responsabilidade intelectual pela construção da informação, que será resultado da pesquisa, seguindo "o curso progressivo e aberto de um processo de construção e interpretação que acompanha todos os momentos da pesquisa" (González Rey, 2011). Assim, a partir do modelo teórico que o orienta a pesquisa, o processo de construção da informação iniciou por meio de elaborações e interpretações, que representam formas de concretização e de organização do processo construtivo-interpretativo, permitindo seu desenvolvimento por meio das categorias que serão expostas na seção seguinte.

No aspecto procedimental, a análise se deu da seguinte maneira: (a) transcrição do áudio do grupo focal: o processo de transcrição possibilitou uma "leitura" inicial do diálogo desenvolvido no grupo e uma avaliação prévia do procedimento, momento em que foi possível ter uma interpretação prévia acerca das informações; (b) leitura flutuante e organização do material da transcrição, numa espécie de pré-análise, que consistiu na sinalização e destaque dos elementos que se mostravam significativos, tendo em vista que desde o início da pesquisa existia o aporte teórico que sustentou esse momento e que o processo ativo de construção do conhecimento está presente em toda a pesquisa; (c) posteriormente foi feita a leitura sistemática que proporcionou a identificação dos indicadores. Que são "elementos que adquirem significação graças à interpretação do pesquisador, ou seja, sua significação não é acessível de forma direta à experiência, nem aparece em sistema de correlação" (González Rey, 2011, p. 112). O indicador só se constrói sobre a base de informação implícita e indireta, pois não determina nenhuma conclusão do pesquisador em relação ao estudado; representa só um momento hipotético no processo de produção da informação; (d) a partir da identificação dos indicadores passou-se para a construção das categorias temáticas, que são instrumentos do pensamento que expressam não só um momento do objeto estudado, mas o contexto histórico-cultural em que esse momento surge como significado e, com ele, a história do pesquisador, que é elemento relevante na explicação de sua sensibilidade criativa. (González Rey, 2011, p. 60)

Diferente da compreensão da definição de categorias como fragmentação dos dados coletados, na Epistemologia Qualitativa esse processo revela a construção teórica que o pesquisador elabora a partir das informações produzidas com os participantes no momento empírico.

Em razão da caracterização do processo de análise pode-se compreender que os resultados encontrados devem ser vistos como dinâmicos e 
abertos a novas interpretações, rompendo com a concepção de resultados finais e universais que se esgotam em uma única pesquisa (González Rey, 2011).

\section{Resultados e Discussão}

O estudo buscou evidenciar o modo como o protagonimo juvenil socioambiental foi vivenciado pelos jovens, considerando as suas múltiplas determinações e as implicações na constituição do sujeito ético-político. Para esses jovens o protagonismo surge como produto e produtor de novas relações consigo e com os outros seja por meio de transformação pessoal, pela promoção de autonomia coletiva, pela possibilidade de organização sociopolítica e pela ampliação do compromisso coletivo e de compromisso político.

A seguir são apresentados os resultados da pesquisa por meio da construção de quatro categorias temáticas: Protagonismo socioambiental como meio de transformação pessoal; Protagonismo socioambiental e promoção de autonomia coletiva; Protagonismo socioambiental e organização sociopolítica; Protagonismo socioambiental e ampliação do compromisso coletivo político.

\section{Protagonismo Socioambiental como Meio de Transformação Pessoal}

$\mathrm{O}$ envolvimento com o coletivo jovem voltado para questões socioambientais caracterizou-se em torno dos significados que envolvem conquistas e transformações pessoais e constituição do sujeito ético-político, conforme salientam os discursos a seguir:

A minha conquista foi mais pessoal, porque desde o princípio, desde criança eu não gostava de meio ambiente. Mas com o tempo, com as conversas, seminários e aulas, eu comecei a refletir o que seria o meio ambiente para mim e pra outras pessoas que estavam e estão ao meu lado. Com o tempo, fiquei interessado em ler livros sobre meio ambiente ... com o tempo eu gostei muito, eu gostei mesmo do meio ambiente, tanto é que eu quis aprofundar mais e mais e par- ticipar de grupos, de palestras, aulas, até curso técnico eu fiz de florestamento. Quando eu comecei a fazer o curso técnico eu amei, amei, amei. (JM1)

O discurso de JM1 revela que o protagonismo socioambiental promoveu uma transformação do distanciamento com as questões que até então caracterizava seu modo de ser. $\mathrm{O}$ grupo lhe permitiu um caminhar voltado ao compromisso enquanto um sujeito ético-político e na busca da participação social em prol do bem comum. No discurso de JM1, verifica-se que o protagonismo brota do envolvimento em eventos que possibilitavam maior conhecimento sobre o ambiente e a relação mantida com ele, de tal forma que com "conversas, seminários e aulas, eu comecei a refletir o que seria o meio ambiente para mim". Ter conhecimentos sobre o meio ambiente é compreendido pelo participante como conquista-transformação para a sua vida pessoal implicando também na apropriação de uma ética ambiental. É a ética ambiental que distingue o sujeito ecológico na apreensão de uma série de valores e crenças que o constituem como tal (Santos, 2016). Esse jovem protagonista se apropria de capacidades que considera vitais para um mundo transformado, compatível com o ideal de pessoas melhores e comportamento sustentável (Santos \& Higuchi, 2014).

Esse discurso é coerente com a concepção de Vigotski (2001) que concebe o desenvolvimento humano como sendo de natureza social, de modo que o sujeito se constitui nas relações sociais. Assim, o fenômeno mencionado pelo participante como "conquista pessoal" deve ser entendido como resultante de processos sociais e individuais da construção do conhecimento e que é determinado pelas interações mediadas socialmente. No entanto, o entorno aqui resulta da constatação que além da dimensão relacional, existe a dimensão física, a qual é cenário dos acontecimentos sociais, mas se constituem, por si só, um mundo onde flui a energia vital (Capra, 2003; Fischer, 1994; Gibson, 1966; Gifford, 2005; Ingold, 2000).

Compreende-se, portanto, que o ser humano não nasce pronto, nasce com possibilidades de construção humana e está sempre sujeito a trans- 
formações, conforme novos eventos sejam incorporados ao seu repertório de experiências, $o$ que demanda uma nova significação e, por conseguinte, transformação na sua postura diante do fenômeno significado. No caso da fala de JM1 o fenômeno seria o gosto pelo meio ambiente, que foi modificado processualmente de acordo com as novas experiências que o jovem vivenciou. $\mathrm{O}$ desenvolvimento é percebido, então, de forma entrelaçada às práticas culturais e educativas, incluindo o processo de aprendizagem, conforme indicado pelo jovem, em suas experiências de formação e implicação com a coletividade sobre o mundo em que está engajado.

Esta implicação, desenvolvida na interação social, pode ser interpretada a partir de Lemos e Higuchi (2011), que discutem que toda relação ambiental pressupõe uma relação das pessoas entre elas e delas com o seu meio. Nessa acepção, se constitui uma ética ambiental, no qual implica no silenciamento ou não do outro. Discute-se, desse modo, que o protagonismo socioambiental, proporciona uma conduta de Ética Ambiental entre os jovens para consigo e com o meio ambiente, promovendo transformações em si, com o outro e com o seu entorno.

O protagonismo pode repercutir positivamente no processo educacional e intelectual, na formação política, na qualificação dos relacionamentos interpessoais, no desenvolvimento de comportamentos ecológicos, na responsabilização, solidariedade e na cidadania, como é possível perceber na fala a seguir de JM2.

$E u$, pelo menos, observo que os integrantes do CJ, têm um nivel de criticidade, de olhar para a realidade muito diferente de outros jovens da mesma idade. A gente é um pouco mais altruísta do que algumas pessoas, a gente tem essa capacidade de se colocar no lugar do outro, a gente é bem ético sabe. (JM2)

O discurso de JM2 aponta que a interação social entre os jovens é mediada pelo cuidado com o outro de maneira individualizada e social. Essa mediação se expande aos cuidados ambientais (Boff, 2005).

O discurso desses jovens ambientalistas aponta elementos necessários para o cuidado da vida em sociedade. Neste aspecto, o protagonismo socioambiental apresenta-se como uma possibilidade de transformação de atitudes, de tomada de consciência para responsabilização, de aquisição de conhecimento intelectual, de incremento do nível de criticidade e empatia com o ambiente e com a vida. A interação com o outro, por meio da linguagem, é uma via importante para mudança dos aspectos cognitivos, afetivos e comportamentais pró-ambientais no cuidado com o outro, com a vida, com a sociedade e com o ambiente.

Esses achados coadunam com a fala de Higuchi e Farias (2002) quando afirmam que as ações humanas sobre o mundo provocam mudanças na estrutura da consciência que advêm das vivências individuais e coletivas e que as concepções e formas de compromisso ambiental possuem papel fundamental nas atitudes e condutas dos sujeitos sobre o meio ambiente.

Os aspectos psicossociais motivadores do protagonismo socioambiental dos jovens delineiam-se a partir das relações de amizades que envolvem: troca; experiência; amizade; pensar no coletivo; preocupação com ambiente; aquisição; expansão e conhecimento. Nesse aspecto, as experiências vivenciadas estão relacionadas a motivações que levaram a participação no coletivo jovem.

"Compartilhar experiências e ter aquele diálogo legal, laços de amizade ..." (JM1).

"Vendo os meus amigos que já participavam h algum tempinho e, eu não estava muito por dentro dessa área de meio ambiente. Eu não tava nem aí. Ai aquelas conversas dos amigos me influenciaram" (JM2).

"As amizades que a gente fez não só dentro do CJ, mas com outras instituições parceiras. Temos feito amigos no CJ, amigos no Fórum... ..." (JM3).

Os diálogos revelam que os jovens têm como aspecto motivador para o protagonismo, a amizade, construída e fortalecida pela troca de experiências, permeadas por opiniões afins que vão desde políticas até comemorações de aniversários. O diálogo estabelecido entre os jovens protagonistas, a partir dos discursos de JM1, JM2 e JM3, permitem identificar que eles trocam 
experiências e saberes entrelaçados no aprendizado a partir da realidade socioambiental.

Apresenta-se, na fala dos jovens, a importância da afetividade na construção de posturas políticas em conjunto. Ou seja, a relação de amizade fortalece a possibilidade de diálogo e trocas efetivas entre os jovens. Esses discursos podem ser compreendidos à luz da concepção dialógica de Freire (2000), que defende uma educação sem a perda da criatividade e do elemento afetivo, em que se constrói conjuntamente. A partir de relações concretas e do posicionamento afetivo diante das experiências vivenciadas pelos grupos, é possível estabelecer um diálogo franco e aberto, por meio do qual se torna possível analisar criticamente os problemas de seu mundo.

Além disso, destaca-se a importância da afetividade nos processos semióticos do ser humano, visto que compreendemos de acordo com Aguiar (2006) que o processo subjetivo é construído a partir da vivência de cada sujeito dentro das suas relações interpessoais e intergrupais, onde afetos, valores, hábitos e costumes estão envolvidos. Este processo é bastante visível nos discursos trazidos pelos jovens quando destacam as relações de amizade resultantes das atividades do coletivo jovem.

Outro aspecto relevante, é que o coletivo jovem atua enquanto um espaço para pensar no coletivo. Isso se torna um aspecto motivador para a atuação protagonista deles. Pois, segundo o discurso a seguir de JM1, a sociedade está cada vez mais individualizada e o coletivo jovem possibilita a expressão do comportamento da ética do cuidado

. . . assim, se cada um fizesse a sua parte o mundo seria melhor, porque a sociedade em si, do século XXI, só quer dinheiro. Mas a natureza, os animais ou cada questão que envolva o meio ambiente, a sociedade não tá nem aí. E, assim, o foco da sociedade no Sec XXI é dinheiro, trabalho ou moda . . . (JF1)

O discurso acima apresenta outro aspecto motivador, a preocupação com o meio ambiente em uma sociedade que dá pouca importância para essa discussão, preocupando-se apenas com o imediatismo, individualismo, representados pela preocupação com a moda e com o dinheiro. Para esses jovens estar no coletivo oportuniza a troca, a expansão e a aquisição de conhecimentos sobre educação ambiental a partir de uma perspectiva crítica.

A amizade e dialogicidade, construída pelo protagonismo socioambiental, é fundamentada por meio do comportamento ético ambiental. Sobre esse aspecto, Boff (2003), considera que o comportamento ético se caracteriza como um conjunto de aspirações, valores e princípios orientadores das ações humanas na sua relação com a natureza, a sociedade, as alteridades e consigo mesmo. Desta forma, configura-se uma atitude de responsabilidade e cuidado com a vida, de convivência societária, conservação dos recursos naturais e dos seres por ela habitada, não deixando de considerar o que é regional e cultural.

\section{Protagonismo Socioambiental e Promoção de Autonomia Coletiva}

O protagonismo socioambiental pode promover outro fator importante - a autonomia. Fato que pode ser constatado no modo como foram relatadas as vivências e decisões no coletivo jovem. No discurso de JM2, é possível identificar a relevância da autonomia.

A gente nasceu na verdade de uma política pública, então nos encontros, a gente disse: nós não somos mais política pública, nós não somos filhos do MEC [Ministério da Educação], nós somos um movimento socioambiental de jovens educadores ambientais. Isso foi a conquista maior que a gente teve, bate no orgulho na gente, porque a ideia surgiu da gente, surgiu numa reunião nossa de intercâmbio Manaus-Iranduba. E mesmo quem não foi, se apropriou muito do estatuto, dos encontros, porque sabia que a ideia tinha saido daqui. (JM2)

O protagonismo socioambiental, conforme pôde ser verificado no discurso de JM2, permitiu que os jovens se fizessem autônomos. É possível perceber que eles buscaram por meio de discussões e normas próprias do grupo em encontros e estudos técnicos, o reconhecimento da necessidade de lutar pela sua emancipação enquanto 
coletivo jovem e responsáveis por transformação social, consciente da possibilidade de ir além do que havia sido proposto para eles pelo MEC.

Pensar e agir são elementos inseparáveis nas reflexões libertadoras e de promoção de autonomia. Como a educação é um ato de conscientização, tal ação torna-se (ou pode se tornar) libertadora e transformadora, geradora de mudanças (Loureiro, 2003), assumir um compromisso social a partir da realidade vivida é uma tarefa protagonista que requer do protagonista, por sua vez, que seja capaz de "agir e refletir" (Freire, 1979). Isso exige um exercício de "distanciamento" e concomitante "reflexão sobre" o contexto em que está envolvido para poder objetivá-lo e transformá-lo. Além disso, esse compromisso deve ser realizado por um ser concreto, com existência concreta em uma situação concreta no mundo físico. A perspectiva freiriana considera que não há como comprometer-se verdadeiramente, sem implicar-se de maneira profunda.

As ações desses jovens, portanto, estão atreladas às variadas dimensões que a construção de um pensamento crítico proporcionou a eles, como a busca da transformação social. Essa afirmativa também é corroborada a partir dos discursos a seguir:

"Observa-se a determinação de jovens em mudar a suas cidades e lutarem por suas cidadanias, melhorando os lugares onde vivem" (JM2).

"O CJ dedicou todo um ano para a formação da juventude e para a criação do Pacto pela Juventude que foi assinado por todos os candidatos à prefeitura da cidade de Iranduba" (JM3).

O discurso de JM2 permite verificar que o protagonismo socioambiental trouxe organização política desses jovens, com reflexos concretos na realidade deles, pois conseguiu implantar políticas públicas para a juventude no município. Nesse sentido, identifica-se um discurso racional entre eles, no qual se percebem ativos e que podem intervir em sociedade, atuando no cuidado com meio ambiente, com a juventude e com a vida humana.

A atuação desses jovens reflete-se na ideia de autonomia, discutida por Paulo Freire, como ação esclarecida e livre, entre as alternativas que lhe são apresentadas (Freire, 1996). Segundo essa concepção, a pessoa deve ter capacidade para agir de forma racional, optando entre alternativas que lhe são apresentadas e compreender as consequências de suas escolhas. Assim, respeitar a autonomia é reconhecer que a pessoa e a coletividade são os que devem deliberar e tomar decisões; é considerar os direitos, motivos e razões dos indivíduos (Fortes \& Zoboli, 2004). Por meio dos discursos de JM2 e JM3, esses jovens se identificam como cidadãos ativos e sujeitos das suas histórias. São jovens que assumem condutas e processos organizativos políticos, assumindo a vida em sua totalidade, incluindo sobremaneira uma maior responsabilidade como ambiente em que vivem. Nesse processo de vivências e produções psicossociais, os jovens também mostram que elementos internos e contextuais podem ser coadjuvantes na formação do ser protagonista.

\section{Protagonismo Socioambiental e Organização Sociopolítica}

A participação no grupo socioambiental permitiu aos jovens uma organização política de definição dos lugares e as causas possíveis para incidência política, nas quais poderiam atuar. Ao compor um CJ, o grupo teve que aprender qual era a função dessa organização, o histórico de atuação e quais as possibilidades de ação que se apresentavam a partir dessa composição.

... no começo da nossa atuação como CJ... o grupo nasceu em 2003, mas a gente só entrou no grupo em 2009. Então já tinha toda uma história com ele e quando a gente entrou no grupo a gente não sabia exatamente o quê que o CJ fazia, o quê que era o CJ, então a gente atuava como se fosse um grêmio nas escolas. (JM2)

É perceptível que a atuação política, dos espaços e papéis políticos exercidos foi uma construção por parte dos jovens. Por não saber o que o CJ fazia, a atuação partiu da experiência que eles já haviam acumulado, com a vivência de grêmio estudantil. A partir dessa posição inicial e das demandas encontradas para atuação, em conjunto com a criatividade dos jovens, 
foram inauguradas novas possibilidades para a construção de um modo de atuação política a partir da realidade pelos jovens vivenciada.

Diante de tal configuração da atuação dos jovens, pauta-se na compreensão de cidadania desenvolvida por Stamato (2008), que é exercida enquanto processo histórico, contextualizado, e extremamente complexo, não ocorrendo de forma mágica, espontânea, natural, em função apenas de uma determinada faixa etária ou etapa de desenvolvimento. É possível perceber que, em conformidade com o que defende a autora, para que os jovens se tornassem cidadãos atuantes, foi necessária uma ação educativa que permitiu a eles transcender o papel de mero ator social, aprendendo a ler o mundo, a realidade onde deveriam atuar e o grupo que passaram a compor, de forma crítica e atuar nesse contexto de forma transformadora.

Dessa reflexão conclui-se que aprender a atuar no CJ e organizar-se politicamente não foi um processo natural e sim uma relação de fortalecimento do sujeito e do grupo, na qual a coletividade se transformou em espaço de descoberta e de vivência da alteridade (Stamato, 2008). A participação dos jovens nos grupos possibilitou que estes pudessem viabilizar conquistas que trouxeram benefícios socioambientais, além de contribuir para o fortalecimento da identidade e autonomia dos jovens.

... ter aprendido a lutar politicamente é uma conquista, porque tem muitos grupos de CJ que não aprenderam e o CJ Amazonas aprendeu a fazer isso. Teve uma conquista que eu acho que foi muito importante foi o fato de a gente ter realizado o encontro nacional. Que o encontro nacional foi uma ideia nossa do CJ daqui, tanto que a coordenação foi do Amazonas mesmo o evento acontecendo lá em Goiás. . . . a ideia foi nossa e a pilha também para fazer foi nossa, a gente na verdade, a primeira ideia era que $o$ encontro acontecesse aqui, mas como o Amazonas é longe do resto do país aí ficava muito mais caro. (JM2)

"Nós não somos filhos do MEC, nós somos um movimento socioambiental de jovens educadores ambientais" (JM2).
Analisa-se as conquistas como processo de fortalecimento da autonomia e uma questão de desenvolvimento humano, pois as experiências das conquistas possibilitaram uma construção identitária-política, sobre o modo como as experiências são vivenciadas e passam a compor o significado para si.

Essa compreensão coaduna-se ao entendimento de desenvolvimento humano constituído com base num processo dialético do homem com o social (Oliveira, 2008; Vigotski, 2001) e a adolescência como uma construção histórica e cultural (Ozella, 2003). O desenvolvimento da atuação política protagonista dos jovens se deu por meio da mediação deles com o mundo, num processo dialético complexo, no qual ocorreram transformações qualitativas no modo de atuar e se articular politicamente. A atuação política pautou-se na realidade concreta e contribuiu para o desenvolvimento de aspectos individuais de cada jovem, de autonomia, identidade política participativa e protagonista, num imbricamento de fatores internos e externos, constituindo a unidade dialética objetividade/subjetividade em que o indivíduo e o social são inseparáveis e o particular contém em si o universal (Lane, 1995; Oliveira, 2008; Vigotski, 2001).

Compreende-se, dessa maneira, que a atuação protagonista, no âmbito do CJ, funcionou como elemento de mediação do processo de emancipação dos jovens e de mudança de sua forma de inserção na sociedade, culminando na conquista de resultados relevantes no âmbito da atuação política ambiental.

\section{Protagonismo Socioambiental e Am- pliação do Compromisso Coletivo Políti- co}

A atuação desses jovens no coletivo, a partir da mobilização da sociedade civil, contribuiu para a construção de um compromisso político, principalmente, por meio dos representantes e movimentos sociais. Alguns autores reafirmam que o compromisso ambiental é representado pelas ações decorrentes do reconhecimento das limitações da natureza e aplicações de medidas que perpassem o cuidado com a vida e o meio em que ela se desenvolve numa articulação in- 
terdependente de responsabilidades individuais e coletivas (Boff, 1999; Leff, 2001, 2003).

". . . criação do Pacto Pela Juventude que foi assinado por todos os candidatos à prefeitura da cidade de Iranduba. Ação Politica da Juventude de 2012, a gente mobilizou aquela cidade inteira, foi incrivel" (JM3). ... a gente fez um evento na câmara dos vereadores com 99 das reivindicações que era o Plano Popular de Governo, com as reivindicações de um monte de gente do sindicato dos trabalhadores rurais, grupo de mulheres e, tudo foi a gente que mobilizou. Fomos atrás, e ai fomos ver quais eram as reivindicações deles. Passamos para um documento, nós passamos eu acho que muito tempo escrevendo, transcrevendo tudo aquilo e esquematizando não isso aqui é parecido com esse então tira esse aqui então vai ter não essa parte vai ser só educação, então vai ter uma parte só da educação, cultura, esporte, juventude e assim por diante. (JM3)

E fechamos o documento, no final chamamos de Pacto da Juventude que era uma coisa que estava acontecendo lá na Bahia, que era uma iniciativa do conselho nacional da juventude e que era pacto da juventude, só que o pacto deles era uma folha com alguns acordos sobre juventude, só que como a gente tinha feito um negócio imenso que contemplava todo mundo que era sociedade civil da cidade, o nosso era pacto da juventude, mas era um plano popular de governo, de vinte e tantas páginas, de 23 páginas. E isso foi legal porque a gente convidou todos os candidatos eram 6 candidatos à prefeitura, os 6 foram e os 6 assinaram. (JM2)

Os discursos dos jovens apresentam um compromisso político com a coletividade e são formas protagonistas de vivenciar a participação política, no sentido de subverter as limitações que são impostas diversas vezes à participação política juvenil.

Segundo Carrano (2006), existe uma íntima relação entre as condições materiais de vida e a participação social e política. De modo que o agravamento das condições de vida da maioria da população jovem brasileira incide diretamente no aumento da sensação de insegurança no presente e das incertezas quanto à vida futura. E é nesse quadro de crescente instabilidade e desesperança diante das capacidades do Estado em promover direitos, bem-estar social e segurança, que se estabelecem os principais entraves e podem-se formular os desafios na forma de políticas públicas democráticas para o desenvolvimento da cidadania juvenil.

Pode-se perceber que no caso dos jovens do CJ há uma produção política participativa, criativa e comprometida com o social. Compreendemos, assim, com base em Carrano (2006), que as esferas de protagonismo juvenil podem ser espaços de formulação, crítica, criação de públicos reflexivos e enfrentamento de problemas que podem ou não se transformar em políticas públicas. A transformação das reivindicações coletivas apresentadas pelos jovens em compromisso público foi resultado da capacidade dos atores coletivos de pautarem os problemas socioambientais junto às esferas políticas.

O mesmo autor (Carrano, 2011) define que os grupos são laboratórios da vida pública democrática, entretanto, suas práticas precisam ser experimentadas nos territórios de encontro entre os diferentes sujeitos das cidades. A composição do CJ, portanto, pôde favorecer o encontro dos jovens, que, provocados pelas questões emergentes, puderam rearticular as práticas políticas vigentes em conformidade com suas percepções e demandas.

\section{Considerações Finais}

Este artigo buscou apresentar as formas como os jovens participantes de um coletivo jovem de meio ambiente vivenciaram o protagonismo socioambiental juvenil. As compreensões apresentadas pelos jovens circunscrevem o protagonismo socioambiental no âmbito de atitudes de cuidado com o ambiente, de promoção da autonomia da juventude e do fortalecimento de amizades e troca de experiências entre os integrantes do grupo. Os jovens sinalizaram para organização política, conquistas obtidas em virtude articulação política e ampliação do 
compromisso coletivo político. Constatou-se, portanto, que através de grupos mobilizadores e de atuação ambiental, os jovens assumem um compromisso social, solidário e político que os permite se constituírem em agentes transformadores da sua realidade. Além disso, o grupo os empodera para que possam contribuir para a formação de uma sociedade voltada aos cuidados com o meio ambiente balizados numa conduta ética. É possível afirmar, a partir desse estudo, que o cuidado com o meio ambiente pode ser um subsídio de transformação, desalienação e fortalecimento político da juventude. O protagonismo socioambiental, com base nos significados atribuídos, possibilita também a participação social, fazendo com que eles se sintam implicados com a justiça social despertando a cooperação e a solidariedade, princípios importantes para a sobrevivência humana e da terra com seu ecossistema.

A atuação política dos jovens contribui para a constituição de sujeitos críticos e participativos no processo de transformação social, com exercício da cidadania comprometida com o coletivo. Esse movimento juvenil permite desconstruir a recorrente associação da juventude com a violência ou como uma fase da vida em que o sujeito não quer assumir responsabilidades transformadoras. Além disso, a atuação protagonista socioambiental tem papel primordial no que concerne à formação de processos identitários dos jovens. Foi a partir do momento que passaram a integrar o grupo socioambiental e se organizar nesse âmbito que os jovens passaram a perceber o poder de agência de uma juventude articulada politicamente e isso foi marcante para que a atuação deles obtivesse conquistas relevantes no aspecto ambiental, para o reconhecimento deles enquanto grupo atuante e fortalecimento do coletivo, culminando no comprometimento de diversos outros representantes políticos com as causas que eram por eles defendidas.

Embora esse estudo tenha limitações no que se refere à abrangência da amostra, os resultados nos permitem conclamar a importância de criação de políticas públicas que fortaleçam o potencial participativo e protagonista dos jovens, em diversas esferas sociais, meio ambiente, educa- ção, artes, esportes, etc. É imprescindível que a juventude tenha possibilidades desenvolvimento, no que diz respeito às relações sociais e à atuação cidadã crítica nos contextos onde vivem. Considera-se que que o protagonismo socioambiental é um desses caminhos para a potencialização da capacidade que os jovens possuem de ser agentes de transformação social e construtor de sua história, comprometidos com o bem-estar social e as alteridades.

\section{Contribuições dos Autores}

Substantial contribution in the concept and design of the study: Maria Inês Gasparetto Higuchi

Contribution to data collection: Iolete Ribeiro da Silva, André Luiz Machado das Neves, Eleonora Celeste Farkas Félix Pereira.

Contribution to data analysis and interpretation: Iolete Ribeiro da Silva, André Luiz Machado das Neves, Fernanda Priscilla Pereira Callegare, Maria Inês Gasparetto Higuchi.

Contribution to manuscript preparation: Iolete Ribeiro da Silva, André Luiz Machado das Neves, Fernanda Priscilla Pereira Callegare.

Contribution to critical revision, adding intelectual content: Iolete Ribeiro da Silva, André Luiz Machado das Neves, Fernanda Priscilla Pereira Callegare, Maria Inês Gasparetto Higuchi.

\section{Conflitos de interesse}

Os autores declaram não ter conflito de interesse relacionado à publicação deste manuscrito.

\section{Referências}

Aguiar, W. M. J. (2006). A pesquisa junto a professores: Fundamentos teóricos e metodológicos. In W. M. J. Aguiar (Ed.), Sentidos e significados do professor na perspectiva sócio-histórica: Relatos de Pesquisa (pp. 11-22). São Paulo, SP: Casa do Psicólogo.

Albuquerque, D. S. (2012). Protagonismo socioambiental: $O$ olhar de jovens participantes de programas de educação ambiental (Trabalho de conclusão de Curso, Universidade Federal do Amazonas, Manaus, AM, Brasil). 
Alisat, S., \& Riemer, M. (2015). The environmental action scale: Development and psychometric evaluation. Journal of Environmental Psychology, 43, 13-23. doi: 10.1016/j.jenvp.2015.05.006

Boff, L. (1999). Saber cuidar: Ética do humanocompaixão pela terra. Petrópolis, RJ: Vozes.

Boff, L. (2003). Ethos mundial. Rio de Janeiro, RJ: Sextante.

Boff, L. (2005). Virtudes para um outro mundo possivel (Vol. 2). Petrópolis, RJ: Vozes.

Capra, F. (2003). Conexões ocultas: Ciência para uma vida sustentável. São Paulo, SP: Cultrix.

Carrano, P. (2006) Juventude e participação no Brasil: Interdições e possibilidades. Democracia Viva, 30, 3-05.

Carrano, P. (2011). Jovens, territórios e práticas educativa: Desafios à autonomia e à convivência. Revista Teias, 12(26), 7-22.

Fischer, G. (1994). Psicologia social do ambiente. Lisboa: Instituto Piaget.

Fortes, P. A. C., \& Zoboli, E. L. C. P. (2004). Bioética e Promoção de Saúde. In F. Lefèvre \& A. M. C. Lefèvre (Eds.), Promoção de saúde: A negação da negação (pp. 26-47). Rio de Janeiro, RJ: Vieira e Lent.

Freire, P. (1979). Educação e mudança (12. ed.). Rio de Janeiro, RJ: Paz e Terra.

Freire, P. (1996). Pedagogia do oprimido (17. ed.). Rio de Janeiro, RJ: Paz e Terra.

Freire, P. (2000). Pedagogia da autonomia: Saberes necessários à prática educativa (15. ed.). São Paulo, SP: Paz e Terra.

Freire, P. (2001). Educação e atualidade brasileira (2. ed.). São Paulo, SP: Instituto Paulo Freire.

Gibson, J. J. (1966). The senses considered as perceptual systems. Boston, MA: Houghton Mifflin.

Gifford, R. (2005). O papel da psicologia ambiental na formação política ambiental e na construção do futuro. Revista Psicologia USP, 16(12), 237-247. Recuperado em http://pepsic. bvsalud.org/scielo.php?script=sci_arttext\&pid $=\mathrm{S} 1678-51772005000100025$

González Rey, F. L. (2003). A subjetividade e seu significado atual na construção do pensamento psicológico. In F. L. González Rey (Ed.), Sujeito e subjetividade: Uma aproximação históricocultural (pp. 199-265). São Paulo, SP: Thomson.
González Rey, F. L. (2011). Pesquisa qualitativa em psicologia: Caminhos e desafios. São Paulo, SP: Pioneira Thomson.

Higuchi, M. I. G., \& Farias, M. S. M. (2002). Pequenos guias do bosque da ciência: Trajetória de uma experiência de educação ambiental com crianças na Amazônia. Manaus, AM: Instituto Nacional de Pesquisas da Amazônia.

Ingold, T. (2000). The perception of the environment: Essays on livelihood, dwelling and skill. London: Routledge.

Lane, S. T. M. (1995). A mediação emocional na constituição do psiquismo humano. In S. T. M. Lane \& B. B. Sawaia (Eds.), Novas veredas $d a$ psicologia social (pp. 55-63). São Paulo, SP: Brasiliense.

Lazzaretti de Souza, A. P., Finkler, L., Dell'aglio, D. D., \& Koller, S. H. (2010). Participação social e protagonismo: Reflexões a partir das conferências de direitos da criança e do adolescente no Brasil. Avances en Psicología Latinoamericana, 28(2), 178-193. Recuperado em http:// www.scielo.org.co/scielo.php? script $=$ sci_ arttext\&pid=S1794-47242010000200003\&lng= en\&tlng $=\mathrm{pt}$

Leff, H. (2001). Saber ambiental: Sustentabilidade, racionalidade, complexidade, poder. Petrópolis, RJ: Vozes.

Leff, H. (2003). A complexidade ambiental (E. Wolff, Trad.). São Paulo, SP: Cortez.

Lemos, S. M., \& Higuchi, M. I. G. (2011). Compromisso socioambiental e vulnerabilidade. Ambiente \& Sociedade, 14(2), 123-138. doi: 10.1590/S1414-753X2011000200009

Loureiro, C. F. (2003). Emancipación, complejidad y método histórico dialéctico: repensar las tendencias en educación ambiental. Tópicos en Educación Ambiental, 5(13), 21-30.

Ministério do Meio Ambiente. (2005). Coletivos Jovens de Meio Ambiente: Manual orientador (pp. 1-40). Brasília, DF: Autor.

Oliveira, M. K. (2008). Vygotsky: Aprendizado e desenvolvimento, um processo sócio-histórico. São Paulo, SP: Scipione.

Ozella, S. (2003). Adolescências construídas: A visão da psicologia sócio-histórica. São Paulo, SP: Cortez. 
Santos, E. S. (2016). A ética de adolescentes de Manaus diante de dilemas socioambientais na Amazônia (Dissertação de mestrado, Programa de Pós-Graduação em Ciências do Ambiente e Sustentabilidade na Amazônia, Universidade Federal do Amazonas, Manaus, AM, Brasil).

Santos, E. S., \& Higuchi, M. I. G. (2014). Formação do cuidado e responsabilidade de práticas sustentáveis. In M. I. G. Higuchi \& G. C. Azevedo (Eds.), Ecoethos da Amazônia: Problemáticas socioambientais para um pensar e agir responsável (pp. 100-110). Manaus, AM: Instituto Nacional de Pesquisas da Amazônia.

Silva, P. A. (2010). Subjetivação presente no discurso do protagonismo juvenil. Revista Brasileira de Adolescência e Conflitualidade, 12-18. doi: 10.17921/2176-5626.\%25n2p\%25p

Stamato, M. I. C. (2008). Protagonismo juvenil: Uma práxis sócio-histórica de ressignificação da juventude (Tese de doutorado, Pontifícia Universidade Católica, São Paulo, SP, Brasil).
Vigotski, L. (2001). Pensamento e linguagem. São Paulo, SP: Martins Fontes.

Ziglio, L. A. I. (2012). Redes socioambientais e a cooperação internacional: GARSD (Tese de doutorado, Faculdade de Filosofia, Letras e Ciências Humanas, Universidade de São Paulo, SP, Brasil). Recuperado em http://www.teses.usp.br/ teses/disponiveis/8/8136/tde-27092012-113608/ 